\title{
La representación de la infancia en la publicidad: panorama por el marco deontológico español
}

\author{
Ana $\mathrm{M}^{\mathrm{a}}$ MEDINA HEREDIA ${ }^{1}$ \\ Alfonso MÉNDIZ NOGUERO ${ }^{2}$ \\ Universidad de Málaga
}

\begin{abstract}
RESUMEN:
La creciente presencia de niños en la publicidad no dirigida a ellos hace que nos planteemos tres cuestiones que afectan muy directamente al principio de protección a la infancia en los medios de comunicación: 1) ¿Hasta qué punto la deontología publicitaria recoge eficazmente esa protección al menor? 2) ¿Qué se dice en los códigos publicitarios acerca de la presencia de los niños en la publicidad: sobre todo, en lo referente a su imagen? 3) ¿En qué medida se cumple lo estipulado en esos códigos? Esas tres cuestiones están en la base de este trabajo, que pretende realizar una panorámica sobre las normas deontológicas publicitarias, analizando críticamente tanto sus aportaciones como sus lagunas o incumplimientos. Tras las conclusiones, ofrecemos un «Decálogo de Buenas Prácticas para la Utilización de la Imagen del Menor en la Publicidad».
\end{abstract}

PALABRA CLAVE: Publicidad; Infancia; Imagen; Deontología; Legislación.

TITLE: The representation of children in advertising: a survey by the frame Spanish ethics

\begin{abstract}
:
The growing presence of children in advertising not directed at them makes us to consider three issues that most directly affect the principle of protecting children in the media: 1) To what extent the advertising ethics effectively protect the principle of protecting children? 2) What sets ethical codes about the presence of children in advertising, especially in regard to his image in the commercials? 3) To what extent are met standard specifications listed above? These three issues are the basis of this work, which aims to conduct an overview of ethical standards in the field of advertising, critically analyzing both their contributions and their shortcomings or failures. Following the conclusions, we offer a «Ten Commandments of Good Practice for the Use of the Image of Child in Advertising».
\end{abstract}

KEY WORDS: Advertising; Children; Image; Ethics; Legislation.

\section{Introducción}

El número 913 de la revista francesa Vogue, correspondiente a diciembre 2010-enero 2011, levantó una enorme polémica en todo el mundo por las páginas de moda en que aparecían unas niñas como modelos publicitarias. Thylane, Lea y Prune, tres niñas de

1 Doctora en Comunicación Audiovisual por la Universidad de Málaga y miembro del Grupo de Investigación sobre «Nuevas Formas Publicitarias y Nueva Economía» (SEJ 396).

E-mail: anacvx@gmail.com

2 Profesor Titular de Comunicación Audiovisual y Publicidad en la Universidad de Málaga. Director del Grupo de Investigación sobre «Nuevas Formas Publicitarias y Nueva Economía» (SEJ 396).

E-mail: amendiz@uma.es 
entre 5 a 7 años, eras las grandes protagonistas de ese número en unas imágenes rutilantes, elaboradas con gran despliegue de medios. Lo que desató la controversia no era que se utilizaran menores como modelos (algo habitual en publicidad, y prácticamente necesario en productos infantiles) sino por la forma en que fueron presentadas: zapatos de aguja, escotes pronunciados, carmín intenso en los labios. Eran niñas vestidas "para matar'... a los siete años. Niñas ataviadas con firmas de alta costura (Versace, Lanvin, Gucci, Yves Saint Lauren, etc.) y maquilladas como adultas, en poses y actitudes claramente sensuales. La polémica alcanzó tal dramatismo, que la editorial decidió el cese fulminante de la redactora jefe de Moda, Carine Roitfeld, el 1 de febrero de 2011.

Este caso nos remite al protagonizado por Armani en el verano de 2007. En su línea de ropa junior, dirigida a niñas de entre 14 y 15 años, vivió una polémica mediática de gran calado cuando, para lanzar su nueva ropa de temporada, utilizó en la publicidad impresa la imagen de dos niñas de 5 años, una de ellas de rasgos orientales, cogidas de la mano, con una ropa y una pose que fueron consideradas poco apropiadas por el Defensor del Menor, Arturo Canalda. Según manifestaba en su denuncia, la imagen de la infancia ofrecida en dicha campaña podía interpretarse como un fomento del turismo sexual. En su escrito, destacó el hecho de que una de las niñas tuviera rasgos orientales, pues ni ellas configuran el target perseguido por la empresa ni el lote de Armani va a ser vendido principalmente en esa zona del mundo. «Con este anuncio -señalaba el Defensor-, Armani está lanzando un doble mensaje: por un lado provoca confusión en los adultos, que asocian esa ropa a la seducción infantil, y por otro, confunde a los niños, que no perciben que se les esté anunciando ropa» ${ }^{3}$.

Estos dos ejemplos ponen de relieve algo de suma importancia: la creciente manipulación de la imagen infantil en los mensajes publicitarios; y, sobre todo, en los mensajes no dirigidos a ellos. Esta evidencia ha hecho que nos planteemos tres cuestiones que afectan muy directamente al principio de protección a la infancia: 1) ¿Hasta qué punto la legislación y la deontología publicitarias recogen eficazmente esa protección al menor? 2) ¿Qué se dice en los códigos éticos acerca de la presencia de los niños en los mensajes publicitarios: sobre todo, en lo referente a su representación en ellos? 3) ¿En qué medida se cumplen las especificaciones normativas antes indicadas?

Decididos a llevar a cabo esta indagación, organizamos el presente estudio como una amplia panorámica sobre la normativa deontológica en el ámbito de la publicidad española, tratando de analizar tanto las aportaciones como las lagunas e incumplimientos de los principales textos. Para ello, recurrimos a una metodología de base hermenéutica, muy común en el ámbito jurídico y deontológico, que hemos desarrollado en dos fases sucesivas: análisis de los principales códigos deontológicos sobre publicidad e infancia, en contraste con los informes de seguimiento publicados hasta la fecha; y elaboración de una propuesta final, que hemos denominado «Decálogo de Buenas Prácticas para la Utilización de la Imagen del Menor en la Publicidad».

3 “El Defensor del Menor denuncia la nueva campaña de Armani”, Elmundo.es, 13/03/2007, http://www.elmundo.es/elmundo/2007/03/09/comunicacion/1173457665.html, visitada el 10/10/2011. 


\section{Publicidad e infancia en los Códigos deontológicos}

La realidad legislativa en materia publicitaria abarca de manera insuficiente la relación infancia-publicidad. Por este motivo, los agentes implicados en la actividad comercial han generado normas y mecanismos que establezcan unos criterios deontológicos compartidos, como muestra la declaración de los europarlamentario en el Segundo Encuentro Anual con los Medios organizado por el Parlamento Europeo ${ }^{4}$.

La Asociación Autocontrol para la Autorregulación de la Comunicación Comercial constituye hoy por hoy el principal organismo dedicado a la autorregulación publicitaria ${ }^{5}$. Esta organización de autodisciplina fue creada en 1996 al amparo de la Directiva 84/450/CEE sobre publicidad engañosa, que promueve los controles voluntarios de los países miembros en materia de comunicación comercial, así como lo hacen con posterioridad a la ley de la Unión Europea, la Ley 34/1988 General de Publicidad, y la Ley 22/1999 de 7 de junio, de modificación de la Ley 25/1994, de trasposición de la Directiva Europea Televisión sin Fronteras.

En ella, empresas anunciantes, agencias de publicidad, medios de comunicación y asociaciones sin ánimo de lucro gestionan el sistema para procurar la corrección de la actividad publicitaria desarrollada en España, «velando por el respeto a la ética publicitaria y a los derechos de los destinatarios de las comunicaciones comerciales» ${ }^{6}$.

Para cumplir sus objetivos, Autocontrol cuenta con un Código de Conducta Publicitaria basado en el Código de Prácticas Publicitarias de la Cámara Internacional de Comercio. También cuenta con un sistema extrajudicial de resolución de controversias en materia publicitaria, que aplica el Código de Conducta, y que trabaja mediante el Jurado de la Publicidad, compuesto por expertos de reconocido prestigio en Derecho, Economía y Comunicaciones Comerciales, que dota a este órgano de un elevado nivel de credibilidad y autoridad técnica, no sólo a nivel nacional, sino también internacional, mediante la pertenencia de Autocontrol a la European Advertising Standards Alliance (EASA).

Las principales normas deontológicas que afectan a la relación de la infancia y la publicidad, prestando especial atención a la aparición del menor en los mensajes comerciales, son las siguientes:

\footnotetext{
4 "Parlamentarios y medios defienden la autorregulación publicitaria", Elmundo.es, 21/10/2011, http://www.elmundo.es/elmundo/2011/10/21/comunicacion/1319187843.html, visitada el 22/10/2011.

5 Sobre este punto: PERALES, A. (2009): «La regulación voluntaria en el ámbito de la publicidad», http://www.auc.es/Documentos/, visitada el 11/12/2011.

6 Estatutos de la Asociación Autocontrol para la Autorregulación de la Comunicación Comercial, 11.V.1995 (última revisión: 26.IV.2011), art. 5. Disponible en: http://www.autocontrol.es/pdfs/estatutos_2011.pdf.
} 


\subsection{Normas de admisión de publicidad del Ente Público Radio-Televisión Española}

El 17 de abril de 1990, la Dirección General de Medios de Comunicación Social del Ministerio de Relaciones con las Cortes y de la Secretaría del Gobierno acuerda las normas que regirán la inserción publicitaria en la radio y televisión pública española, modificando las anteriores normas que a tal efecto se había promulgado la propia dirección del Ente, de fecha de 16 de diciembre de 1983 y de 10 de mayo de $1988^{7}$.

Estas normas (publicadas en el Boletín Oficial del Estado $\mathrm{n}^{\circ} 95$ de 20 de abril de 1990, pp. 10679-10680) constituyen el primer avance en autorregulación, dentro de la esfera publicitaria en nuestro país, con especial mención de los menores de edad. Se trata de normas internas de un ente de carácter público, como el de RTVE, cuya mención es meramente contextual, ya que hoy día la situación de RTVE ha cambiado sustancialmente. Así, la Ley 8/2009, de 28 de agosto, de financiación de la Corporación de Radio y Televisión Española, ha suprimido la publicidad de TVE (en su disposición transitoria primera), supresión que entró en vigor en enero de 2010.

El capítulo III está dedicado a las Normas de protección a la infancia, y en él se recoge la necesidad de que la publicidad emitida no perjudique a los menores, mediante el cumplimiento de los siguientes criterios:

- No incitará directamente a los menores a la compra de un producto, explotando su inexperiencia o su credulidad, ni a persuadir a sus padres o a terceros para que lo hagan (art. 13a).

- No explotará la especial confianza de los menores en sus padres, profesores y otras personas (art. $13 \mathrm{~b}$ ).

- No presentará a menores en situaciones peligrosas o susceptibles de inspirar actitudes violentas, injustas, insolidarias o antipedagógicas (art. 13c).

- En cuanto a la publicidad de juguetes (art. 14), RTVE se aplican las siguientes normas de admisión publicitaria:

- Se rechazará la publicidad de juguetes que exalten el belicismo, la violencia o que reproduzcan armas, así como los que utilicen medios que puedan ser peligrosos para los niños.

- No se admitirá la publicidad de juguetes que exageren las facilidades de ejecución de los productos de modelaje o construcción.

- La publicidad debe dejar claro si el mecanismo del juguete es manual o automático, evitando confusión en cuanto a los efectos de animación.

- No se suscitará confusión en relación a los elementos que se venden con el juguete o de forma separada, ni en cuanto al tamaño del mismo.

- Se expresará la edad destinataria del juguete.

- Los juguetes deben acreditar su cumplimiento de las normas de inocuidad.

7 Un estudio sobre la efectividad de esa normativa en la práctica publicitaria puede verse en: MÉNDIZ, A. (1988), «El principio jurídico de protección a la infancia en la publicidad infantil de TVE», en: Innerarity, D. y Vaz, A. (eds.), Información y Derechos Humanos, Pamplona, EUNSA, 1987, pp. 313-324. 
En el capítulo IV sobre publicidad de determinados bienes, actividades o servicios, en lo relativo al alcohol, el texto del Ente público advierte de que no se presentará a menores consumiendo alcohol o como protagonistas de anuncios de bebidas alcohólicas. En lo referido al uso de menores en la publicidad, se aporta la siguiente afirmación: «los niños actuarán y hablarán con naturalidad y no emitirán juicios o valoraciones impropias de su edad».

$$
* * *
$$

Desde nuestra perspectiva, este código aporta precisión en lo referente al binomio infancia-publicidad, aun tratándose de un texto deontológico pionero. Abarca aspectos fundamentales y lo hace con suficiente especificidad. En lo referente a la aparición del menor resulta encomiable la prohibición de que el menor aparezca presentado en situaciones peligrosas o que inspiren actitudes «antipedagógicas».

Sobre la «intervención de niños en los anuncios», RTVE se fija como criterio el que los niños no pueden ser los actores principales de un anuncio, «salvo en productos dedicados exclusiva o preferentemente a la infancia o de los que ésta sea beneficiaria, o que se refieran a salud, higiene, ropa, literatura, alimentación, elementos deportivos, juegos educativos y juguetes infantiles» (art 15, capítulo III). Aunque la excepción se perfila bastante amplia, dada la dificultad de determinar de qué producto o servicio no es de algún modo beneficiaria la infancia, RTVE empieza por poner límites a esas apariciones de menores en los spots televisivos.

\subsection{Convenio de autorregulación de las cadenas de televisión en relación con de- terminados contenidos referidos a la protección de la infancia y la juventud}

El 26 de marzo de 1993, el Ministerio de Educación, las Consejerías Autonómicas con competencias educativas y las cadenas de televisión firmaron un convenio para mejorar el control de los contenidos televisivos, especialmente en lo referido al público infantil y juvenil.

Uno de los frutos de este convenio ha sido la creación del Consejo Asesor de Televisión en Cataluña, que en 1996 cambió su nombre por Consejo Audiovisual de Cataluña, y que tiene, entre otras funciones, la de impulsar actuaciones positivas de televisión para las familias y el personal docente, como reconocía $\mathrm{M}^{\mathrm{a}}$ Ángeles González Estremat, Directora General de Ordenación Educativa de la Consejería de Educación de la Generalitat de Cataluña, en el informe sobre la Ponencia para analizar el desarrollo del convenio (21 de diciembre de 2008) ${ }^{8}$.

Asimismo, algunas cadenas de televisión han elaborado con posterioridad códigos de conducta, como es el caso de Antena $3 \mathrm{Tv}$, que lo estableció en 18 de agosto de 1997, tras ser aprobado por el Consejo de Administración de la cadena. En él subraya

8 Cfr: http://www.senado.es/tpubhtml/I0613.html 
el objetivo de respetar escrupulosamente «la normativa sobre contenidos en la televisión, fomentando los valores éticos y humanos y prestando especial atención en los horarios infantiles a las recomendaciones de los organismos dedicados a la protección de los menores» $\left(\mathrm{n}^{\mathrm{o}} 3\right)$, y establece los criterios de creación del «defensor del espectador», una figura cuya misión será atender las quejas y sugerencias de la audiencia y transmitirlas a las instancias de las direcciones correspondientes. «El Defensor del Espectador será también el interlocutor con los organismos públicos encargados de velar por el cumplimiento de la normativa sobre televisión, protección del menor y defensa del consumidor» $\left(\mathrm{n}^{\circ} 4\right)$. En la misma línea se manifiesta el documento «Política de Publicidad responsable del Grupo Antena 3», de Noviembre de $2010^{9}$.

$$
* * *
$$

Ha sido, sin duda, un primer paso. A este convenio corresponde el logro de implicar por vez primera a las cadenas de televisión en un proceso autorregulador. Algunas consejerías autonómicas, como la catalana y la andaluza, han desarrollado a su amparo los Consejos Audiovisuales, figura que todavía tiene mucho por hacer en la defensa efectiva del menor en la publicidad.

\subsection{Código deontológico para publicidad infantil}

Al margen de estas primeras iniciativas autorreguladoras, el 14 de diciembre de 1993 se firmaba el primer «Código Deontológico para Publicidad Infantil», en el seno del sector juguetero ${ }^{10}$. La Asociación Española de Fabricantes de Juguetes (AEFJ) y la Unión de Consumidores de España (UCE) se asociaban en un acuerdo de respeto a los menores de 15 años, una audiencia considerada en el mismo texto como «influenciable y vulnerable». Fue la iniciativa pionera en este campo, y desarrolló unas directrices que pretendían ser más ilustrativas que restrictivas. Dentro de sus fundamentos, el Código reconoce la necesidad de promover la creación de anuncios de buen gusto, que contengan referencias a conductas positivas, beneficiosas y pro-sociales, así como el fomento de una relación constructiva entre padres e hijos.

En resumen, este Código marca el camino a seguir en materia de autorregulación publicitaria, que se resume en las siguientes directrices:

Directriz 1: Presentación de los productos y reclamaciones. Los anunciantes deberán examinar el mensaje publicitario para estar seguros de que no provocará equívocos, ni defraudará ni informará erróneamente a los niños.

Directriz 2: Identificación de la Publicidad. Los anuncios deben separarse claramente de los programas y mostrar que están dirigidos a los niños. No deben

Cfr: http://www.grupoantena3.com/nuevaa3tv/doc/PoliticaPublicidadResponsable.pdf Cfr: http://www.anunciantes.com/descargas/Convenio_juguetes.pdf 
usarse situaciones, escenarios y estilos evocadores que confundan a los niños sobre la identidad de la comunicación que están recibiendo.

Directriz 3: Previsión de las ventas. No se utilizará una excesiva presión comercial para lograr el consumo infantil, evitando estrategias que inviten a los niños a pedir a los padres la compra del producto, así como generar en los menores la urgencia de la compra mediante expresiones de inmediatez o exclusividad, ni sugerir que la compra aportará al usuario prestigio, habilidades o cualidades determinadas.

Directriz 4: Información y rectificaciones. Las informaciones complementarias del mensaje publicitario deben expresarse en el lenguaje y los medios más fácilmente comprensibles por la audiencia infantil.

Directriz 5: Presentaciones comparativas. Las presentaciones comparativas deben hacerse en virtud de las características reales de los productos objeto de la comparación.

Directriz 6: Apoyo y promoción a través de personajes de programas y personajes del mundo editorial. Los apoyos personales (de expertos, famosos, etc.) deben reflejar la realidad de las experiencias y creencias de quien las defiende, diferenciando bien lo que es publicidad de lo que es contenido editorial en el medio en que se difunda el mensaje publicitario. Los niños no deben utilizarse para dar testimonio formal. No obstante, esto no impide que hagan comentarios espontáneos sobre temas en los cuales podrían tener un interés natural evidente.

Directriz 7: Premios, promociones, concursos. El uso de premios, promociones o concursos debe ser cuidado atentamente, ya que aumenta el atractivo del producto y puede ser fuente de explotación de la inmadurez infantil.

Directriz 8: Premios. Los mensajes sobre posibles premios asociados al producto deben expresarse de forma sencilla y clara, y de forma secundaria a la información sobre el producto.

Directriz 9: Clubes infantiles. La palabra «club» debe usarse sólo cuando se cumplan los requisitos de interactividad, continuidad y exclusividad, y no debe equivocar a los niños sobre supuestos beneficios por el mero resultado de la compra del producto anunciado.

Directriz 10: Concursos. No se pueden dar expectativas falsas sobre la posibilidad de ganar los concursos publicitarios o sobre las características del premio.

Directriz 11: Seguridad. No deben presentarse a los niños los productos inadecuados para ellos, así como tampoco aquellos productos para niños mostrados con personajes de edad inferior a la recomendada para su uso y disfrute.

No se mostrará el uso peligroso o inadecuado del producto, y se promoverá la aparición de adultos acompañando a los niños cuando los productos puedan poner en peligro su seguridad.

No se incitará a los niños a entrar en lugares extraños o a conversar con desconocidos. 
Tampoco se mostrarán niños o adultos en situaciones inseguras o en actos perjudiciales para sí mismos o para los demás.

El Código es, sin duda alguna, un gran avance en materia deontológica, pero en la práctica se ha revelado absolutamente ineficaz. Por encargo de la Comisión de seguimiento de estas normas, los autores Martínez Pastor, Pérez-Ugena, y Salas (2010) analizaron los spots de juguetes dirigidos a niños y el cumplimiento de la normativa deontológica y jurídica en esta materia. Atendiendo a las directrices 1,3 y 4 del presente Código, este estudio encuentra incumplimientos en un $25,9 \%$ de una muestra de 379 spots. Las infracciones más repetidas han sido las relativas a leyendas ilegibles $(2,60 \%)$ y a la incitación al consumo a través de expresiones como «ahora» $\mathrm{o}$ "solo» $(2,11 \%) \mathrm{o}$ mediante la referencia a la página web del producto $(41,48 \%)$; aunque este incumplimiento se considera «potencial» ya que puede entenderse como información añadida al producto ofertado.

\subsection{Código de Conducta Publicitaria}

El 19 de diciembre de 1996, la Asociación Autocontrol para la Autorregulación de la Comunicación Comercial aprueba un «Código de Conducta Publicitaria», que será posteriormente modificado en la Asamblea General Ordinaria de 14 de abril de 1999 y en la de 26 de abril de $2011^{11}$. Entre sus normas deontológicas, destacan los principios básicos de respeto a la comunicación publicitaria y a su valor dentro del buen funcionamiento del mercado, así como el respeto a la legalidad y a la Constitución.

La publicidad, como afirma el apartado A de este código, no deberá abusar nunca de la buena fe de los consumidores, ni explotar el miedo, la violencia o comportamientos ilegales como argumento de compra, respetando las buenas costumbres y el buen gusto imperantes en la sociedad. No deberán alentarse prácticas peligrosas fuera del contexto de propiedad del producto anunciado, no sugerirá discriminación por la causa que sea, ni atentará contra la dignidad de la persona, ni contra sus derechos inalienables al honor, a la intimidad y a la propia imagen. Tampoco se permitirá fomentar los comportamientos dañinos con la naturaleza. El código de Autocontrol establece que la publicidad debe ser identificable como tal, sea cual sea su medio o forma, y no deberá ser engañosa sino veraz, en las menciones a las características del bien o servicio, así como a su precio, condiciones jurídicas y económicas de adquisición y uso, naturaleza, cualificaciones y derechos del anunciante, servicios post-venta y limitaciones de la oferta.

En el apartado D, el Código de Conducta Publicitaria de Autocontrol trata temas como la garantía de los productos anunciados, la disponibilidad, los ensayos compara-

11 Cfr: http://www.autocontrol.es/pdfs/Cod_conducta_publicitaria.pdf 
tivos, los testimonios, las comparaciones y las campañas con causa social, entre otros aspectos menos relevantes para nuestro estudio. Sí destacamos el apartado E sobre Protección de niños y adolescentes. En él, Autocontrol expone que la publicidad dirigida a niños deberá ser extremadamente cuidadosa, y no deberá explotar la ingenuidad, inmadurez, inexperiencia o credulidad natural de los niños o adolescentes, ni abusar de su sentido de la lealtad. Asimismo, esta publicidad no deberá contener declaraciones o presentaciones visuales que puedan producirles perjuicio mental, moral o físico. Se tendrá especial cuidado, afirma el texto, en la presentación realista del producto, adaptándolo a las capacidades del público infantil. El código concluye con una especial mención a la protección de la salud, mediante la evitación de publicidad que incite a sus receptores, especialmente a los adolescentes, a adquirir pautas o comportamientos que puedan resultar nocivos para su salud.

$$
* * *
$$

Lo más interesante de este Código, sobradamente conocido tanto en el ámbito profesional como en el académico, es que otorga a la Asociación Autocontrol un triple papel de referencia: como árbitro en los conflictos deontológicos, como intérprete de las normas de ética publicitaria y como maestro para la elaboración de una doctrina que efectivamente defienda los derechos de los menores en el ámbito de la publicidad.

\subsection{Código de Autorregulación de la Publicidad Infantil de Juguetes}

La Asociación Española de Fabricantes de Juguetes (AEFJ) firmó, diez años más tarde (14.VI.2003), un acuerdo con la Asociación de Autorregulación de la Comunicación Comercial (Autocontrol) para que apoyase la función realizada por la Comisión de seguimiento creada al efecto en la aplicación de este código. Ese Convenio de aplicación del Código Deontológico para Publicidad Infantil fue ampliado en un documento de $2010^{12}$.

Ese mismo año, en diciembre de 2010, el sector juguetero materializa en un código su deseo de ahondar en la autorregulación como herramienta para regular la comunicación comercial dirigida al público infantil. El texto, que entra en vigor en abril de 2011, quiere ser un compendio de las normas deontológicas existentes en esta materia, pero actualizando su contenido a los nuevos soportes y formatos desarrollados por las nuevas tecnologías de la comunicación. Entre sus principales virtudes se encuentra la exhaustiva mirada a la publicidad en internet, y también la definición de los productos que no se consideran juguetes y que, por tanto, no son regulados por este código.

$$
* * *
$$

12 Código de Autorregulación de la Publicidad Infantil de Juguetes, AEFJ y Aso. Autocontrol, junio de 2010 . 
A pesar de su carácter parcial, por abarcar exclusivamente al sector de los fabricantes de juguetes, esta norma posee un importante valor como elemento cohesionador de los textos ya existentes. Además, resulta muy provechoso para el discurso deontológico general en torno a la infancia y la publicidad la actualización de sus contenidos y, particularmente, los criterios planteados en torno a la figura de los prescriptores, que limita para evitar la influencia no deseada en el público infantil.

\subsection{Criterios interpretativos en materia de publicidad televisiva y menores ${ }^{13}$}

La Secretaría de Estado de Telecomunicaciones y para la Sociedad de la Información (SETSI) y la Asociación para la Autorregulación de la Comunicación Comercial (Autocontrol) firman, el 19 de diciembre de 2003, unas pautas de actuación en cuanto a la publicidad televisiva y su relación con los menores, lo que fue conocido como «Comisión de seguimiento del Acuerdo para el fomento de la autorregulación de la publicidad televisiva».

Este acuerdo comprende tres partes: 1. Publicidad dirigida a menores. 2. Protección de los menores frente a la publicidad: restricciones horarias o de bloques de programación y 3 . Presencia de menores en la publicidad.

En la primera parte, se alude a la especial vulnerabilidad de los menores, especialmente aquellos con edades comprendidas entre los 0 y los 13 años, frente al contenido publicitario, y se establece una serie de criterios a tener en cuenta y respetar para su protección.

Destacamos los siguientes:

- las exigencias especiales de veracidad en los mensajes publicitarios, especialmente los procedentes del sector juguetero, evitando inducir a error mediante sus afirmaciones u omisiones. El acuerdo incluye determinaciones concretas sobre el modo de introducir las informaciones adicionales, por ejemplo.

- El evitar la aparición de personajes famosos que puedan influir en la asimilación del mensaje por parte del público infantil. Ante esto, el texto distingue entre varios supuestos: la prohibición expresa de que aparezcan presentadores o personajes de programas infantiles, a excepción de anuncios que incluyan una promoción que guarde relación directa con un programa o espacio de ficción, separando bien ambos contenidos, y la prohibición de que aparezcan personajes famosos muy populares entre los menores, estando permitido si son famosos que guardan menos popularidad entre ellos o si se trata de campañas de información o educativas.

- Se considera que las telepromociones, o mensajes publicitarios asociados a un programa utilizando las mismas características del programa al que se asocia, explotan la especial confianza de los menores, por no ser claramente diferen-

13 Disponible en:

http://www.mityc.es/dgdsi/mediosaudiovisuales/contenidos/ProteccionMenor/Documents/CriteriosTV.pdf 
ciables. Por eso se establece una serie de requisitos de aceptación de esta práctica:

- que se deslinden ambos contenidos a través de medios ópticos y acústicos.

- no se podrán utilizar los mismos presentadores que en el programa.

- no se podrán mostrar los nombres del programa en que se inserta.

- estas limitaciones desaparecen si la campaña es de concienciación social, informativa o educativa.

- La televenta dirigida a la infancia está permitida, siempre y cuando respete unos criterios básicos: a) que su contenido no pueda perjudicar al menor, b) que no le incite a la compra o a persuadir a otros de la compra, c) que no explote la confianza de los menores en padres, profesores u otros, d) que no presente a los menores en situaciones de riesgo y e) que no induzca a error, especialmente en la publicidad de juguetes, en cuanto a las características del producto, la capacidad o aptitudes necesarias para su uso.

- Se prohíbe la publicidad dirigida a menores que pueda incitarles a comportamientos violentos o antisociales, o fomentar abusos, negligencias o conductas agresivas.

La segunda parte del texto hace referencia a la protección de los menores frente a la publicidad, especialmente en lo relacionado con las restricciones horarias o de bloques de programación. En este sentido, el acuerdo de SETSI y Autocontrol advierte de la prohibición de emitir, durante el horario de protección, desde las 6 a las 22 horas, anuncios cuyo contenido tenga un claro componente adulto, y pueda dañar el desarrollo físico, moral o mental de los menores, así como aquellos que contengan elementos explícitos en materia sexual, salvo que su fin sea educativo.

La tercera parte alude a la aparición de menores en la publicidad. SETSI y Autocontrol están de acuerdo, y así lo firman en este texto de autorregulación publicitaria, en los siguientes apartados al respecto:

1. La aparición de menores en publicidad dirigida al público adulto es completamente lícita, en observancia de las leyes 34/1988 General de Publicidad, 25/1994 de Televisión sin Fronteras, modificada por la Ley 22/1999, y la Ley Orgánica 1/1996 de Protección Jurídica del Menor. La única limitación que se plantea en el presente acuerdo es la de que esta utilización no implique «menoscabo de su honra o reputación, o sea contraria a sus intereses» (art. 4.3 de la Ley Orgánica del Menor) o «presente al niño en situaciones de peligro» (art. 16.1.c de la Ley de Televisión sin Fronteras).

2. Para la utilización de menores en publicidad televisiva, deberá contarse con la autorización expresa del menor, si sus condiciones de madurez lo permiten, o, de no ser así, la autorización previa por escrito de su representante legal. Este permiso deberá ponerse en conocimiento del Ministerio Fiscal, para no incurrir en una intromisión ilegítima del ámbito de protección de la Ley Orgánica 1/1982 sobre Protección Civil del derecho al Honor, la Intimidad y la Propia Imagen en su artículo 7.6. 
3. Sobre la base de la transposición de la directiva europea Televisión sin Fronteras, y lo recogido en el artículo de la misma ya citado en el punto 1, la prohibición de mostrar a menores en situaciones peligrosas respeta la excepción siguiente: a) cuando exista una causa justificada. El texto advierte de que esta salvedad debe interpretarse restrictivamente, es decir, que sólo se considerará motivo justificado cuando obedezca a fines claramente didácticos y comprensibles a todas las edades. En otros supuestos, se cumplirán las restricciones horarias ya expresadas en el apartado segundo de este código. Si los personajes que incurren en esas situaciones son adolescentes y jóvenes, este precepto no resultaría de aplicación, salvo cuando el público infantil pueda encontrar dudoso el carácter irreal de las imágenes y tender a su imitación.

$$
* * *
$$

El acierto principal de este acuerdo es que aborda todas las facetas que convergen en la relación del público infantil con el mensaje comercial, aunque sus directrices resultan poco específicas. En las dos primeras partes, sus indicaciones más concretas se limitan a la vertiente económica de los mensajes (veracidad y claridad en la presentación de la información), resultando poco precisa en lo referente a la capacidad de los anuncios para cambiar o fomentar valores y estilos de vida. Respecto a la utilización de menores en publicidad, sus indicaciones son de escasa concreción.

\subsection{Convenio de Cadenas de Televisión y Criterios orientadores para la clasificación de programas}

Desde 1993, las cadenas de televisión a nivel nacional y el gobierno español comparten un proceso de autorregulación de las actividades televisivas para proteger la especial singularidad de la audiencia infantil. Todas las televisiones nacionales que están emitiendo en 2002 firman una serie de principios que deben guiar la programación de contenidos televisivos, en concreto en lo relativo a la audiencia infantil. Se trata de unas guías inspiradas en normas ya vigentes, como la propia Constitución Española, que no privan a cada medio de su propia línea editorial o de sus normas deontológicas internas. Con ese motivo, el 13 de junio de 2002 nace el Convenio de Cadenas de Televisión y los Criterios orientadores para la clasificación de programas televisivos. Dos años más tarde, las cadenas de televisión y el gobierno firman el Acuerdo para el Fomento de la Autorregulación sobre Contenidos Televisivos e Infancia, con fecha de 9 de diciembre de 2004, y el Código de Autorregulación sobre contenidos televisivos e infancia, y, posteriormente, la ampliación de dicho acuerdo, el 12 de junio de 2006.

El Convenio entre Antena 3 Televisión, Radiotelevisión Española (RTVE), Publiespaña (Tele5), Sogecable (Canalplus), la Federación de Organismos de Radio y Televisión Autonómicas (FORTA), la Asociación para la Autorregulación de la Comunicación Comercial (Autocontrol) y la Asociación Española de Anunciantes (AEA), 
hace suya las directivas europeas de Televisión sin Fronteras, y establece la responsabilidad de las cadenas de televisión de respetar las normas y principios expuestos en las mismas, así como en la trasposición al ordenamiento jurídico español. También recoge el texto la responsabilidad gubernamental de controlar este cumplimiento, mediante el Ministerio de Ciencia y Tecnología, para lo que apuntan la creación de un procedimiento, en el seno de la Asociación Autocontrol que, impulsando la autorregulación del sector, permita la cooperación mutua para la «detección y corrección preventivas de la publicidad eventualmente ilícita en televisión». El texto del convenio establece la mecánica del control, la recogida de incidencias y su procesamiento por medio del Jurado de la Publicidad.

Este convenio es importante en la medida en que marca un camino: inspirado en el espíritu y los principios del Código de Conducta de la Asociación Autocontrol, este convenio supone la primera iniciativa de autorregulación televisiva a gran escala. Junto a él, se establecen los criterios sobre contenidos audiovisuales permitidos o no para el consumo de menores, diferenciando entre los «especialmente recomendados para la infancia», «para todos los públicos», «no recomendados para menores de 7 años», «no recomendados para menores de 13 años» y «no recomendados para menores de 18 años». Otra cosa es quién decide lo que entra en una u otra categoría, punto que aún está por dilucidar. Y pendiente queda también una correcta aplicación y un seguimiento de su cumplimiento en las cadenas de televisión.

\subsection{Código de Autorregulación sobre Contenidos Televisivos e Infancia}

En diciembre de 2004 nace el Acuerdo para el Fomento de la Autorregulación sobre Contenidos Televisivos e Infancia, firmado por RTVE, Antena 3 Tv, Telecinco, Sogecable, y el Gobierno, en las personas de la vicepresidenta primera del Gobierno, $\mathrm{M}^{\mathrm{a}}$ Teresa Fernández de la Vega, y el Ministro de Industria, Turismo y Comercio, José Montilla Aguilera ${ }^{14}$. En él, se expresa el deseo de reforzar la autorregulación de los contenidos televisivos y la protección de la infancia y la juventud ante la programación televisiva, así como los mecanismos creados al efecto, en desarrollo y cumplimiento del mandato de la Disposición Adicional Tercera de la Ley 25/1994 de trasposición de la directiva europea Televisión sin Fronteras. Este acuerdo viene acompañado del Código que establece los criterios concretos de materialización.

El Código de Autorregulación sobre contenidos televisivos e infancia desarrolla una serie de principios que pretenden compatibilizar entre sí, y el propio texto lo recoge en su preámbulo, valores «que informan el actual Estado social y democrático 
de derecho: la libertad de expresión con respeto a los derechos de la personalidad; interdicción de la violencia; la discriminación y la intolerancia, y la protección de la infancia y la juventud». Su principal objetivo es la protección legal de los menores respecto de la programación televisiva emitida en el horario que va desde las 6 a las 22 horas, considerando franjas reforzadas (con más posibilidad de audiencia infantil menor de trece años) de 8 a 9 horas y de 17 a 20 horas, aumentándose durante los festivos y periodos vacacionales.

En materia de publicidad, o aplicables a ésta, el acuerdo reconoce entre sus principios:

- el deber de las cadenas de garantizar el respeto a los derechos fundamentales de los menores que participen en la programación televisiva (1.a).

- evitar la incitación a los niños a la imitación de comportamientos perjudiciales o peligrosos para la salud, especialmente la incitación al consumo de drogas y el culto a la extrema delgadez (1.d).

- evitar los mensajes o escenas de explícito contenido violento o sexual que carezcan de contenido educativo o informativo en los programas propios de la audiencia infantil, así como en sus cortes publicitarios (1.f).

- no se utilizará a menores en imitaciones de comportamiento adultos que resulten vejatorias (2.f).

En el apartado 4, referido a la publicidad, el código refiere su asunción de lo establecido en el acuerdo de 19 de diciembre de 2003 firmado por la Secretaría de Estado de Telecomunicaciones y para la Sociedad de la Información (SETSI) y la Asociación de Autorregulación de la Comunicación Comercial Autocontrol, del que hablamos en el punto 5 .

Como recoge el primer informe elaborado en el seguimiento de estos acuerdos, con el fin de «conferir credibilidad al Código y otorgarle confianza pública», se crean dos órganos que garanticen su cumplimiento:

- El Comité de Autorregulación

- La Comisión Mixta de Seguimiento

El Comité de Autorregulación está compuesto por representantes de los operadores firmantes del acuerdo (Televisión Española, SA; Antena 3 de Televisión, SA; Gestevisión Tele 5, SA, y Sogecable, SA), además de un productor independiente de contenidos televisivos y de un periodista. Sus funciones incluyen:

- La emisión de dictámenes a instancia de parte (dudas de los operadores, quejas de los espectadores) sobre la idoneidad de contenidos concretos, indicando si se aprecian o no inconvenientes para la emisión; en caso afirmativo, el sentido en el que deben ser subsanados, o bien si la emisión sólo puede producirse fuera del horario de protección reforzada o del horario protegido.

- La tramitación ante los operadores, en caso de su admisión, de dichas dudas y quejas.

- La elaboración de informes de actividad periódicos que se remitirán a la Comisión Mixta de Seguimiento. 
La Comisión Mixta de Seguimiento está compuesta paritariamente por un representante de cada una de las cuatro televisiones firmantes del acuerdo arriba mencionadas y cuatro representantes de las principales organizaciones sociales involucradas en el ámbito regulado por el Código: Plataforma de Organizaciones de Infancia (POI), organizaciones de padres de alumnos (CEAPA y CONCAPA) y Consejo de Consumidores y Usuarios (CCU). La Administración asume la Secretaría de la Comisión, con voz pero sin voto, con sendos representantes del Ministerio de Industria, Turismo y Comercio y de Presidencia del Gobierno.

Las funciones de la Comisión incluyen:

- La recepción de dudas y quejas y su traslado al Comité de Autorregulación.

- La emisión de dictámenes sobre el cumplimiento del Código y la elaboración de un informe anual sobre el tema.

- La actuación a través de otras instancias en caso de inatención por parte de los operadores a los requerimientos del Comité de Autorregulación.

$* * *$

Aunque según la Comisión de seguimiento las quejas presentadas y aceptadas disminuyen de manera ostensible en los dos últimos años (12 en 2006, 31 en 2007, 71 en 2008, 37 en 2009 y 22 en 2010), estos datos han sido contestados desde diferentes sectores. De hecho, se contradicen con los ofrecidos por informes independientes como los generados por el grupo GICOMSOC, de la Universidad Rey Juan Carlos, que ha realizado durante años un seguimiento independiente por encargo de la Presidencia del Gobierno. Entre otros, encontramos un elevado número de vulneraciones cometidas entre el 9 de septiembre y el 31 de diciembre de 2008 y el 1 de julio y el 30 de septiembre de 2009. Las infracciones ascienden a 4.889 y 5.838, respectivamente. De éstas, alrededor del $30 \%$ se califican como vulneraciones graves, localizadas básicamente en las películas en el tercer trimestre de 2009, y en las series, los informativos y los programas de actualidad social en el último trimestre de 2009. Los concursos, la publicidad (excluyendo las autopromociones) y los dibujos animados apenas presentan infracciones de gravedad $\mathrm{A}^{15}$.

Por su parte, el Observatorio de Publicidad y Sociedad del Centro Universitario Villanueva, en colaboración con organizaciones de telespectadores, ha venido realizando también informes de seguimiento y actualización de este código con periodicidad semestral. El VIII Informe de Seguimiento ${ }^{16}$ destaca que las televisiones incumplen una media de 7,50 veces al día el horario de protección a la infancia, siendo la Sexta y A3 las cadenas que menos respetan a los pequeños.

Las cadenas de televisión asociadas en estos acuerdos (a las que se adhieren La Sexta, Net N y Veo N, así como los operadores asociados a la Federación de Organis-

15 FernándeZ, A. y LóPeZ de Ayala, M. C. (2011): «Televisión e infancia: cinco años después del código de autorregulación», Revista Latina de Comunicación Social, ${ }^{\circ}$ 66, pp. 31-62.

$16 \mathrm{http}: / /$ www.atr.org.es/informes/8Informe_ATRVillanueva.pdf 
mos de Radio y Televisión Autonómicos (FORTA) en junio de 2006) mantienen la actualidad y seguimiento de su fidelidad al mismo en la página web creada al efecto www.tvinfancia.es, a través de la cual se anima a los espectadores a tramitar las reclamaciones sobre lo que consideren contenido inadecuado para el menor que se emite en un horario también inadecuado. Como los propios asociados afirman, «de ese papel activo de los espectadores depende también la utilidad que el Código de Autorregulación pueda tener para la sociedad» ${ }^{17}$.

\subsection{Código de Autorregulación de la Publicidad de Alimentos Dirigida a Menores, Prevención de la Obesidad y Salud (Código PAOS) ${ }^{18}$}

El Ministerio español de Sanidad y Consumo, amparado por las recomendaciones de la Organización Mundial de la Salud (OMS) se planteó la Estrategia NAOS (Estrategia para la Nutrición, Actividad Física y Prevención de la Obesidad) para disminuir la prevalencia de obesidad y sobrepeso de la población, así como las consecuencias de esas enfermedades en el ámbito de la salud pública y en sus repercusiones sociales.

En ese marco, la Federación de Industrias de Alimentación y Bebidas (FIAB) promovió, en marzo de 2005 la creación de un código de autorregulación publicitaria para el cuidado de los mensajes comerciales dirigidos a menores de edad. Este código, como el propio texto recoge en su introducción, está en línea con los Principios de la Publicidad de Alimentos y Bebidas de la Confederación de Industrias AgroAlimentarias de la Unión Europea (CIAA), aprobados en febrero de 2004. El código reconoce la especial vulnerabilidad de los menores de 12 años, y en su desarrollo acude abundantemente al Código del sector Juguetero presentado con anterioridad. Así, a lo largo del texto, va aplicando al ámbito de la alimentación y la bebida las directrices del Código Deontológico para Publicidad Infantil referentes a la claridad de diferenciación de los mensajes comerciales respecto al resto de comunicación, a la necesidad de no explotar la ingenuidad del menor, ni mostrar violencia y agresividad gratuitas o situaciones de riesgo, a hacer comprensible las informaciones adicionales que pudieran ser necesarias, a evitar la presión comercial excesiva para el consumo del producto, a mostrar exclusivamente beneficios inherentes al uso del mismo y a cuidar el uso de promociones, premios, concursos, etc.

Sobre la utilización de personajes de ficción o presentadores de programas infantiles, el Código PAOS es tajante: estos no participarán en la publicidad dirigida a menores a no ser que ese programa o serie guarde relación directa con alguna promoción,

17 Informe de evaluación sobre la aplicación del Código de Autorregulación de Contenidos Televisivos e Infancia. Marzo 2005- Marzo 2006. p.21, en: http://www.tvinfancia.es/Informes/InformeAnual20052006.htm

18 Un estudio pormenorizado de este código en: PÉREZ-UGENA, A., MERTÍNEZ, E. y PERALES, A. (2010): «La regulación voluntaria en materia de publicidad. Análisis y propuestas a partir del caso PAOS», Revista TELOS, http://sociedadinformacion.fundacion.telefonica.com/, visitada el 12/12/2011. 
caso en el cual se diferenciará marcadamente las imágenes publicitarias de aquellas que muestran el contenido de la ficción.

El control del cumplimiento de este acuerdo recae, explícitamente, en el Jurado de la Publicidad de Autocontrol, quien queda encargado de resolver las eventuales reclamaciones que puedan surgir en torno a la publicidad de las empresas adheridas al mismo.

Desde septiembre de 2009, este Código, suscrito por el Ministerio de Sanidad y Consumo, la Industria Alimentaria y Autocontrol, cuenta con la adhesión de las cadenas de televisión de la Federación de Organismos de Radio y Televisión Autonómicos (FORTA) y la UTECA (Unión de Televisiones Comerciales), a excepción de TVE, que deja de emitir publicidad en enero de 2010. Las cadenas asumen, de este modo, el contenido de las normas éticas contempladas en el Código PAOS, que se aplicará a todos los anunciantes, hayan firmado o no el acuerdo, ya que son los operadores los que se comprometen a respetar su contenido.

Desde su entrada en vigor, en marzo de 2005, hasta septiembre de 2009, se estudiaron 1.331 anuncios, de los que 320 salieron adelante con modificaciones, y 68 fueron rechazados ${ }^{19}$. En todo el año 2009, del total de 407 anuncios examinados sobre alimentos y bebidas a ser emitidos en franjas horarias dirigidas a los niños, el $31 \%$ fueron corregidos en alguno de sus elementos, mientras que en 20 anuncios, se aconsejó su no difusión.

Desde su aplicación, el código ha recibido menos de veinte reclamaciones, (17 hasta febrero de 2010), lo que hace deducir un correcto cumplimiento de sus principios. El principal motivo de reclamación en los cinco primeros años de aplicación de este código deontológico ha sido la utilización de personajes famosos de manera indebida, seguida de la presentación de situaciones de consumo inmoderado o hábitos sedentarios, el apremio a la obtención del producto, el llamamiento directo a los niños a adquirirlo, la presentación de éste como sustitutivo de comidas principales o la infravaloración de hábitos de vida saludables ${ }^{20}$. El Código PAOS contaba, a febrero de 2010, con $36 \mathrm{em}$ presas adheridas, un $94 \%$ de la inversión publicitaria en televisión de productos alimenticios para niños.

En materia de salud, la Confederación Española de Organizaciones de Amas de Casa, Consumidores y Usuarios (CEACCU) editó en 2009 un informe sobre «Televisión para los niños $2008 \gg{ }^{21}$ con el objeto de analizar la programación televisiva dirigida a la infancia en relación con sus derechos, en especial con el derecho a la salud, incluida la publicidad, la autopromoción y el patrocinio de programas.

19 «Multas a los anunciantes que promuevan la obesidad infantil», Diario ABC (8-9-2009) en su versión digital, consultado el $8 / 09 / 2009$ en http://www.abc.es/hemeroteca/historico-08-092009/abc/TvyRadio/multas-a-los-anunciantes-que-promuevan-la-obesidad-infantil_1023928165423.html

20 «El 31\% de los anuncios sobre alimentación infantil no supera el primer examen», Diario El Mundo (17-2-2010) en su versión digital, consultado el 18/02/2010 en:

http://www.elmundo.es/elmundosalud/2010/02/17/nutricion/1266419226.html

21 Disponible en: http://www.ceaccu.org/publicaciones/informes 
El trabajo, realizado por un equipo de investigadores dirigidos por el profesor Sánchez de Diego, de la Universidad Complutense, viene a completar una serie de informes que se inició tres años antes de ser aprobado el Acuerdo para el Fomento de la Autorregulación sobre Contenidos Televisivos e Infancia y su consecuente Código y que lo ha incorporado como materia de seguimiento y evaluación, especialmente en lo relativo a las franjas de protección reforzada. Este estudio parte del convencimiento, expresado por sus autores, de que administraciones públicas, madres y padres y consumidores y usuarios deben ser parte de la solución que se dé a la problemática de la televisión y el menor (corregulación). En relación a la publicidad, este trabajo concluye que, dentro del horario de protección reforzada, existe una saturación de publicidad dirigida a menores, fundamentalmente de juguetes y alimentación, y que en ella se emiten contenidos impropios por su componente sexual, violento (especialmente en promoción de videojuegos o autopromoción de contenidos para adultos) y que vulnera con frecuencia lo establecido en el Código PAOS.

Resulta interesante el esfuerzo de este texto por promover los hábitos alimentarios y estilos de vida saludables, y sobre todo por aportar orientaciones concretas a las empresas firmantes, como la de no mostrar el alimento promocionado en cantidades excesivas, ni como sustituto de una de las tres comidas principales (desayuno, almuerzo y cena), o la recomendación de presentarlo dentro de una amplia gama de productos que sugieran una alimentación variada y equilibrada. El amplio seguimiento de las empresas del sector consolida un código que es con seguridad el primer paso en un largo itinerario que deben recorrer de la mano las empresas de alimentación infantil y las instancias que velan por la protección de la infancia.

\subsection{Directrices de Buenas Prácticas de Publicidad de Productos de Software Interactivo $^{22}$}

La Asociación Española de Distribuidores y Editores de Software de entretenimiento (ADESE) se adhirió al Código de Conducta de la industria europea del ramo relativo a la clasificación por edades, el etiquetado, la promoción y la publicidad de productos de software interactivo: el llamado Código PEGI ${ }^{23}$. Ahí se indica la obligatoriedad de incluir la edad recomendada para los usuarios $(+$ de $3,+$ de $7,+$ de $12,+$ de $16,+$ de 18) y la presencia de contenidos nocivos: Discriminación, Drogas, Sexo, Miedo, Violencia, etc. Además de esto, quiso reforzar su compromiso con el respeto a los menores, que exigen una especial protección, mediante la firma de dos convenios: uno con el

\footnotetext{
$22 \mathrm{http} / / /$ www.autocontrol.es/pdfs/pdfs_codigos/Directrices\%20ADESE.pdf

23 Disponible en: http://www.adese.es/index.php?option=com content\&view=article\&id=17\&Itemid=21
} 
Defensor del Menor de la Comunidad de Madrid, en mayo de $2004^{24}$, y otro con la Asociación Autocontrol, en junio de 2005, para la promulgación de unas directrices de buenas prácticas ${ }^{25}$.

$$
* * *
$$

Estas directrices son un paso necesario en la adaptación de la ética publicitaria a los nuevos modos de entretenimiento con los que los menores interactúan de manera creciente. Destacamos la importancia que este documento da a las referencias de clasificación por edades, así como a la obligatoriedad de figurar en la caja de todos los videojuegos. También es interesante -pensando en los padres y educadores que no conocen bien este tipo de diversión- la indicación de contenidos potencialmente nocivos (escenas de droga, sexo, discriminación racial, etc.), como también la restricción para la publicidad de videojuegos clasificados como «+ de 18», «+ de 16» y «+ de 12» en determinados lugares (cercanía a centros educativos), medios de comunicación (revistas o programas radiofónicos infantiles), horarios de emisión (franja protegida) o largometrajes (dirigidos al público infantil o adolescente). Con todo, echamos en falta una más clara y firme declaración los derechos de la infancia en este campo; derechos que, en no pocos casos, son vulnerados en la experiencia vivida por el niño cuando interactúa con ese software de entretenimiento. El ensalzamiento de conductas violentas y agresivamente competitivas deberían encontrar una mayor restricción que el de la simple clasificación por edades.

\section{Discusión}

Los códigos deontológicos en publicidad constituyen un elemento indispensable para el fomento y respeto de la buena praxis en la creatividad publicitaria. Desde las primeras "Normas de admisión de anuncios en RTVE" (1990) a los sucesivos acuerdos que han implicado a los anunciantes, cadenas de televisión, etc. se percibe un progresivo intento de aunar voluntades en el camino de la autorregulación, a la par que se avanza en la especialización de contenidos: la publicidad de juguetes, la de software interactivo, etc. Sin embargo, su efectividad es puesta en duda en cada nuevo estudio que se publica.

La falta de desarrollo legal, tanto en Europa como en nuestro país, ha motivado un creciente trabajo deontológico por establecer directrices que aseguren la buena praxis en la publicidad dirigida a los menores. Así, tanto desde organismos profesionales (Asociación para la Autorregulación de la Comunicación Comercial) como desde sectores relacionados con el consumo infantil (fabricantes de juguetes o empresas de ali-

\footnotetext{
24 Disponible en: http://www.adese.es/pdf/convenios/CONVENIO_DEFENSOR_MENOR_ ADESE.pdf

${ }^{25}$ Disponible en: http://www.adese.es/pdf/convenios/Convenio\%20aDeSe_autocontrol.pdf
} 
mentación) o empresas de comunicación (principalmente, cadenas de televisión), se han suscrito códigos cada vez más precisos y más atentos a las posibilidades seductoras de las nuevas tecnologías. Además, como ratifica la Ley 7/2010 en relación al Código de Contenidos Televisivos e Infancia, los códigos de autorregulación constituyen en ocasiones un anticipo de reformas legislativas, que incorporan con posterioridad las previsiones recogidas en ellos.

Sin embargo, esa vigilancia de los mensajes "dirigidos a la infancia" no revela la misma sensibilidad a los mensajes "protagonizados por la infancia". Se echa en falta una mirada más profunda a lo que supone la participación de la infancia en publicidad, a una definición más neta de su lugar en el imaginario social, que afecta tanto a los menores (como espejo de sí mismos) como a los adultos (como refuerzo de conductas y estereotipos).

Por otra parte, la fuerza de estas reglas recae en la actuación de las comisiones de seguimiento, como el Jurado de Autocontrol, que, sobre la base de la buena voluntad de los asociados, vela por su cumplimiento a partir de las demandas que presentan los consumidores o las empresas afectadas. El problema fundamental de la autorregulación es, precisamente, su carácter voluntario, que imposibilita la universalización de estas reglas y, por tanto, la garantía de ese respeto.

Sigue echándose en falta - de manera cada vez más clara- la existencia de una instancia que, con autoridad reconocida, pueda velar por los derechos de la infancia; sobre todo porque, como reconocen nuestras leyes, esos derechos se anteponen a cualquier derecho comercial o de expresión, por legítimo que sea. En definitiva, una instancia que, ante las infracciones, pueda actuar de forma contundente frente a anunciantes y medios de comunicación, en pro de la salvaguarda de los derechos del niño. La previsión, en la nueva Ley General de la Comunicación Audiovisual, de un Consejo Estatal de Medios Audiovisuales, podría tener consecuencias positivas, tal como esperan anunciantes, familias, publicitarios y expertos del mundo académico.

\section{Propuesta de un Decálogo de Buenas Prácticas para la Utilización de la Imagen del Menor en la Publicidad}

Como aportación concreta a la normativa deontológica sobre infancia y publicidad, proponemos un «Decálogo de buenas prácticas» que trata de sintetizar lo ya señalado en este repaso al marco deontológico. Al mismo tiempo, pretende ayudar a la salvaguarda de los derechos del menor en lo que se refiere a su presencia en los mensajes publicitarios ${ }^{26}$. Estos diez puntos pretenden cubrir la ausencia de una más específica propuesta deontológica sobre la representación de la infancia en la publicidad.

26 Para una justificación exhaustiva de cada una de estas diez propuestas, vid. MEDINA, A.Ma . (2011) Publicidad e Infancia: la imagen del niño en los spots (España, 2007). Tesis doctoral en Comunicación Audiovisual y Publicidad. Universidad de Málaga, junio 2011, pp. 269-457. 
1. La presencia del menor en los mensajes publicitarios debe tener una justificación estratégica y no meramente táctica: bien por ser la infancia la destinataria del producto, bien por ser la beneficiaria de éste en primer o segundo término.

2. En el caso de utilizar la imagen de un niño en un anuncio dirigido al público adulto, sin ser el menor de edad beneficiario del producto, su representación evitará la cosificación del menor como mero vehículo de un deseo irracional de compra, así como su vinculación a características egocéntricas, y destacará cualidades propias de la infancia y de su dignidad como persona.

3. Los valores vinculados a la representación de la infancia deberán ser de naturaleza positiva, contribuyendo a la creación de un discurso constructivo acerca de su imagen y su aportación a la sociedad.

4. Se aconseja la utilización de uno y otro sexo en carácter de igualdad, así como la integración de personajes infantiles con distintos rasgos étnicos, para normalizar la multiculturalidad existente en la sociedad actual.

5. Es preferible evitar la identificación de los varones con cualidades como la agresividad, la competitividad o la creatividad, ni tampoco asociar los valores de la familia, la ternura o la solidaridad exclusivamente con el mundo de las niñas.

6. Se desaconseja presentar al menor en situaciones que no le son propias, especialmente aquellas en las que se realizan actividades peligrosas, que contienen un componente sexual no adecuado a su edad o desarrolladas en espacios no apropiados para él.

7. En lo referente al aspecto físico, la representación de la infancia debe atenerse a los cánones de normalidad (tanto en estatura como en esbeltez), evitando estereotipos que contribuyan a desear una imagen falsa e idealizada del propio cuerpo, e incentiven -aunque sólo sea indirectamente- trastornos de la conducta alimentaria o conflictos emocionales en el menor.

8. Debe rechazarse toda utilización de la imagen del menor como excusa para representar actitudes adultas carentes de responsabilidad y de valores para el correcto desarrollo de la convivencia social.

9. Se desaconseja proyectar una imagen excesivamente infantilizada del menor, procurando que ésta refleje el necesario crecimiento personal y la adecuada madurez de cada etapa de su vida.

10. Cuando el niño aparezca en compañía, especialmente en relación con la familia, los amigos y los miembros del entorno educativo, se aconseja vivamente su representación en una actitud colaborativa y no meramente pasiva. 


\section{Referencias bibliográficas}

\subsection{Artículos, libros e informes}

FERnÁndez MARTíneZ, A. y LÓPEZ DE AyAla LóPEZ, M. C. (2011): «Televisión e infancia: cinco años después del código de autorregulación», Revista Latina de Comunicación Social, $\mathrm{n}^{\mathrm{o}}$ 66, http://www.revistalatinacs.org/11/art/923_Fuenlabrada/02_Ayala.html. DOI: 10.4185/RLCS-66-2011-923-031-062 / CrossRef link, visitada el 12/09/2011.

Martínez Pastor, E., PÉrez-UgenA, A y SAlAS, A. (2010) «Publicidad y juguetes: Análisis de los códigos deontológicos y jurídicos», Pensar la Publicidad, IV, 2, 127-140

MEdina HerediA, A.M . (2011) Publicidad e Infancia: la imagen del niño en los spots (Espa$\tilde{n} a$, 2007). Tesis doctoral en Comunicación Audiovisual y Publicidad. Universidad de Málaga, junio 2011, 654 pp.

MÉNDIZ NogUERO, A. (1988), «El principio jurídico de protección a la infancia en la publicidad infantil de TVE», en Innerarity, D. y Vaz, A. (eds.), Información y Derechos Humanos, Pamplona, EUNSA, pp. 313-324.

Perales, A. (2010): «La regulación voluntaria en el ámbito de la publicidad», http://www.auc.es/Documentos/, visitada 11/12/2011.

PÉREZ-UgenA, A.; MARTÍNEZ, E. Y PERALES, A. (2010): «La regulación voluntaria en materia de publicidad. Análisis y propuestas a partir del caso PAOS», Revista TELOS, http://sociedadinformacion.fundacion.telefonica.com/url-direct/pdfgenerator?tipoContenido $=$ articuloTelos\&idContenido $=2011072809310001 \&$ idioma $=\mathrm{es}$, visitada el 12/12/2011.

Ruiz SAN Román, J.A., GARcía GALERA, Ma C. y FernÁndez Martín, E. (2008): VIII informe ATR-VILLANUEVA seguimiento del código de autorregulación (firmado el 9 de diciembre de 2004) horario de protección reforzada de la infancia, http://www.atr.org.es/informes/8Informe_ATRVillanueva.pdf, visitada el 14/10/2011.

VV. AA. (2007): Televisión para los niños 2008. Análisis de las comunicaciones y contenidos televisivos dirigidos a la infancia y juventud en relación con sus derechos, en especial con el derecho a la salud, Madrid, CEACUU.

\subsection{Códigos Deontológicos sobre publicidad e infancia}

Acuerdo para el Fomento de la Autorregulación sobre Contenidos Televisivos e Infancia, RTVE, Antena 3 Tv, Telecinco, Sogecable y Gobierno, 9.XII.2004.

Código de Autorregulación de la Publicidad de Alimentos Dirigida a Menores (Código PAOS), Federación de Industrias de Alimentación y Bebidas (FIAB), 29.III. 2005.

Código de Autorregulación de la Publicidad Infantil de Juguetes, AEFJ y Asociación Autocontrol, junio de 2010.

Código de Autorregulación sobre Contenidos Televisivos e infancia, Cadenas de televisión y Gobierno de España, 12.VI.2006.

Código de Conducta Publicitaria, Asociación Autocontrol para la Autorregulación de la Comunicación Comercial, 19 de diciembre de 1996.

Código Deontológico para la Publicidad Infantil, Aso. Española de Fabricantes de Juguetes (AEFJ) y Unión de Consumidores de España (UCE), 14.XII.1993. 
Convenio de aplicación del Código Deontológico para Publicidad Infantil, AEFJ y Asociación Autocontrol, 14.VI.2003.

Convenio de autorregulación de las cadenas de televisión sobre contenidos referidos a la protección de la infancia y la juventud, Ministerio de Educación y Ciencia, Comunidades Autónomas y Cadenas de Televisión, 24.III.1993.

Convenio de Cadenas de Televisión y Criterios orientadores para la clasificación de programas, cadenas de televisión y Gobierno, 13.VI.2002.

Criterios interpretativos en materia de publicidad televisiva y menores, Secretaría de Estado de Telecomunicaciones y para la Sociedad de la Información (SETSI) y Asociación Autocontrol, 19.XII.2003.

Directrices de Buenas Prácticas de Publicidad de Productos de Software Interactivo, Aso. Española de Distribuidores y Editores de Software de entretenimiento (ADESE) y Asociación Autocontrol, junio de 2005.

Normas de admisión de publicidad del Ente Público Radio-Televisión Española, Dirección General de Medios de Comunicación Social, 17 de abril de 1990.

Recibido: 2 de enero de 2012

Aceptado: 20 de febrero de 2012 